\title{
O DEVER FUNDAMENTAL DE PAGAR IMPOSTO DE RENDA NO REINO UNIDO
}

Adriano da Nobrega Silva* adrianodanobrega@gmail.com

\section{RESUMO}

O presente trabalho busca analisar a construção do dever fundamental de pagamento do imposto de renda no Reino Unido, em função do caráter pioneiro que as questões tributárias tiveram naquele país.

Palavras-chave: Imposto de renda; Reino Unido; Direito comparado; dever fundamental.

\section{The fundamental obligation of payment of the income tax in the United Kingdom}

\section{ABSTRACT}

This paper analyses the development of the fundamental obligation of payment of the income tax in the United Kingdom, regarding the pionner character of the tax matters in that country.

Key words: Income tax; United Kingdom; Comparative Law; fundamental obligation.

\footnotetext{
* Professor do UniCEUB; consultor legislativo da Câmara dos Deputados; pesquisador do Grupo Integrado de Pesquisa em Finanças Públicas Contemporâneas.
} 


\section{INTRODUÇÃO}

A história é farta de exemplos a demonstrar que a questão tributária está diretamente relacionada aos direitos fundamentais. Uma das manifestações desse fato é a de que, desde a Magna Carta, se pretendeu limitar a instituição de impostos que não tivessem sido aprovados pelo Parlamento (British Library, 2004), afirmando José Casalta Nabais que o pagamento de impostos constitui uma categoria jurídica autônoma, um dever fundamental (1999, p. 35-40) ${ }^{2}$.

Em relação a esse dever fundamental, a cobrança de imposto sobre a renda possui papel de destaque. Isso porque, se, nas sociedades menos evoluídas, a instituição de mero imposto per capita é aconselhável, por ser de fácil arrecadação e administração, não atende à capacidade contributiva dos cidadãos (Clarence, 1968, p. 1). Do mesmo modo, alternativas fiscais, tais como, os impostos aduaneiros (customs duties) e os impostos sobre determinados produtos (excise taxes), apesar de serem mais facilmente administráveis, precisam atender a funções extrafiscais que reduzem ou inviabilizam momentaneamente o caráter arrecadatório (Clarence, 1968, p. 1).

Em virtude dessas razões, o presente estudo procura analisar as relações entre o imposto sobre a renda e os direitos fundamentais no Reino Unido. Será inicialmente realizada contextualização do sistema constitucional do país, apresentando-se suas linhas mestras fundamentais, enfatizando-se a importância das decisões judiciais, passando-se, em seguida, à abordagem das questões tributárias propriamente ditas.

2 Conforme as lúcidas lições de José Casalta Nabais (1999, p. 15-18), um assunto pouco abordado nos tratados de Direito Constitucional é o de que as Constituições prevêem não só direitos fundamentais mas também deveres fundamentais, explicando o autor que essa postura decorre do fato de que as modernas Constituições surgem como forma de limitar o poder e de, conseqüentemente, evitar o abuso dos governantes e, além disso, decorre, ainda, do fato de que muitas das atuais Constituições surgem com o intuito de substituir regimes totalitários anteriores, os quais previam, de modo absoluto, a sujeição do indivíduo em face do Estado.

A postura dominante da doutrina é a de considerar os deveres fundamentais como limites dos direitos fundamentais (Zippelius, 1997, p. 449), sendo tratada a liberdade dos demais indivíduos como limite à própria liberdade; esse posicionamento tem como premissa um dos dogmas do liberalismo, qual seja, o de considerar que a liberdade ou a autonomia do indivíduo constitui um dado anterior ao Estado, sendo, portanto, ilimitada (Nabais, 1999, p. 28-29).

Outro equívoco reside em considerar os direitos fundamentais como decorrentes dos deveres fundamentais, ou seja, o poder público é situado em primeiro plano quando comparado com os cidadãos. Nesse sentido, os deveres fundamentais seriam a manifestação, no plano individual, do poder estatal, ao passo que os direitos fundamentais seriam, apenas, reflexos do poder estatal (Nabais, 1999, p. 32-35). 


\section{SISTEMA CONSTITUCIONAL TRIBUTÁRIO NO REINO UNIDO}

\subsection{Normas constitucionais}

\subsubsection{O papel do Poder Judiciário}

O sistema jurídico do Reino Unido possui peculiaridades que o distinguem dos demais existentes na Europa e que não podem ser adequadamente compreendidas sem o exame de sua evolução histórica.

Em primeiro lugar, deve ser apontado que o feudalismo britânico se deu de modo sui generis: os normandos conquistam a Inglaterra, a qual é dividida em feudos. Os senhores feudais, de origem normanda, estranhos em terra estranha, precisam organizar-se em torno do Rei, sob pena de verem-se subjugados. Por essa razão, os feudos são rigorosamente organizados pelo soberano, em um verdadeiro sistema militar (David, 1998, p. 285).

A principal fonte de onde provém o direito, na época, é o costume. Como em todos os sistemas feudais, existe, nesse período, por evidente, a multiplicidade de costumes locais, válidos apenas nas circunscrições de cada feudo, convivendo com outros costumes conhecidos e cumpridos em todo o Reino. Enquanto os primeiros caracterizam costumes particulares, os últimos compõem a Common Law propriamente dita (Blackstone, 1769, p. $63)^{3}$.

Entretanto, essa prevalência do costume não é suficiente para distinguir o sistema jurídico do Reino Unido dos demais existentes no continente europeu, visto que também vivenciavam, nesse momento histórico, essa experiência. Dois outros fatores contribuíram para a peculiaridade do sistema britânico: a Inglaterra não conhecia, até então, um corpo de regras preestabelecido em um diploma legal, a exemplo do Corpus Juris Civilis (David, 1998, p. 340) e, ao contrário do que se verificava no continente, não era necessário que os juízes ou advogados possuíssem formação universitária ${ }^{4}$ (David, 1997, p. 3).

Blackstone salienta a peculiaridade dos costumes em relação às leis:

3 A prevalência, na Idade Medieval, do costume devia-se ao fato de que poucas eram as pessoas letradas no período (Blackstone, 1769, p. 63). Para Blackstone, duas eram as fontes principais da Common Law: os costumes, reconhecidos como tais em todo o Reino, e as máximas, como a que prevê que o Rei não comete nenhum erro ou que nenhum homem pode ser obrigado a produzir provas contra si mesmo (1769, p. 68).

4 Isso fez com que os eventuais estudos do Direito Romano, empreendidos no período, ficassem restritos ao ambiente acadêmico (David, 1997, p. 3). 
sua instituição original e sua autoridade não se encontram em textos escritos, tais como os atos do Parlamento, mas recebem sua compulsoriedade, sua força jurídica, pelo uso prolongado e imemorial e por sua aceitação universal por todo o Reino (...) esses costumes são antigos como os primeiros bretões e permanecem imodificados e inalterados, mesmo após as muitas mudanças no governo e na população, até os dias atuais. $(1769, \text { p. } 64)^{5}$

Sendo o costume imemorial, convém, como o faz Blackstone, indagar: como um costume pode ser reconhecido e como ele pode ter sua validade determinada? O próprio autor responde: pela atuação dos juízes, nas diversas Cortes existentes no Reino (1769, p. 69) ${ }^{6}$. Isso determina a mudança no modo como a idéia de Direito é considerada no continente europeu, a exemplo da França e do Reino Unido. Enquanto, na primeira, é visto como modo de organização social, com regras de conduta gerais, no segundo, é muito mais o modo pelo qual os conflitos devem ser solucionados no âmbito de um processo judicial (David, 1997, p. 2-3).

Tendo em conta a importância dos juízes na construção do sistema jurídico britânico, convém fazer referência, ainda que superficialmente, à evolução histórica da estrutura do Poder Judiciário do Reino Unido. Inicialmente, as questões jurídicas eram solucionadas por cortes locais (Hundred Courts ou County Courts), com recurso aos costumes existentes na região ou no feudo em que se localizavam, cabendo ao Rei, apenas em escassos casos, o exercício da Justiça (David, 1998, p. 286).

No século XIII, são instituídos os Tribunais Reais em Westminster, originalmente com competências excepcionais - julgamento de causas relativas às finanças reais (Tribunal de Apelação - Exchequer), de questões relativas à propriedade imobiliária e à posse de imóveis (Tribunal de Pleitos Comuns - Common Pleas) e de graves questões criminais relativas à paz do Reino (Tribunal do Banco do Rei - King’s Bench) (David, 1998, p. 287).

Com a instituição das Cortes Reais, passa a haver duas jurisdições distintas: a da Coroa e a dos senhores feudais. Enquanto aquela cuidava das regras e dos costumes comuns em todo o Reino (razão pela qual passou a ser denominada Common $\mathrm{Law}^{7}$ ), os senhores feudais aplicavam apenas as regras e os costumes locais de seu feudo (David, 1997, p. 4).

5 Livre tradução de "their original institution and authority are not set down in writing, as acts of parliament are, but they receive their binding power, and the force of laws, by long and immemorial usage, and by their universal reception throughout the kingdom (...) these customs are as old as the primitive Britons, and continued down, through the several mutations of government and inhabitants, to the present time, unchanged and unadulterated.".

6 O papel dos juízes no Reino Unido irá explicar, posteriormente, por que o controle da constitucionalidade dos atos compete aos juízes nos Estados Unidos (judicial review), ao passo que, na França, essa espécie de controle é prerrogativa do Poder Legislativo.

7 Ressalte-se que a Common Law não se confunde com o denominado Direito Comum conhecido, no mesmo período, no Continente Europeu. 
Por serem as Cortes Reais mais eficientes no julgamento dos litígios, os particulares passaram a dirigir suas questões ao seu julgamento. No mesmo sentido, tais Cortes, desejando ampliar sua competência mediante ficções jurídicas, conheceram muitos dos litígios verificados no Reino Unido sob o argumento de que interessavam à Coroa (David, 1997, p. 4). Além disso, era interessante para o Rei a ampliação da competência das Cortes Reais, porque a administração da justiça real proporcionava grandes lucros à Coroa (David, 1998, p. 288).

Além dos julgamentos de causas de interesse da Coroa, releva observar que outra importante função dos tribunais foi a de fazer valer os princípios estabelecidos nos contratos de domínio firmados contra os abusos e os arbítrios do soberano porque a concentração do Poder nas mãos do soberano, no Reino Unido, deu-se antes do que se verificou no Continente (Miranda, 1997, p. 123). Em função dos abusos advindos da concentração de poder, o mecanismo encontrado no Reino Unido, desde o século XIII, para solucionar os conflitos entre o soberano e os súditos, não foi a edição de leis fundamentais, as quais rompiam com toda a estrutura jurídica anteriormente existente, mas sim a elaboração de contratos de domínio $^{8}$, os quais confirmavam os direitos e as liberdades já presentes nos costumes existentes e buscavam limitar o poder do soberano (Canotilho, 1997, p. 69).

A aplicação dos compromissos estabelecidos nos contratos de domínio pelos juízes constituiu o que, no Reino Unido, ficou conhecido como rule of law, o qual pode ser compreendido como:

os princípios, as instituições e os processos que a tradição e a experiência dos juristas e dos tribunais mostraram ser essenciais para a salvaguarda da dignidade das pessoas frente ao Estado, à luz da idéia de que o Direito deve dar aos indivíduos a necessária proteção contra qualquer exercício arbitrário de poder. (Miranda, 1997, p. 130).

Além disso, tendo em conta o importante papel desempenhado pelos julgados em

8 O primeiro desses diplomas a ser mencionado é a Magna Carta (1215), o qual marca a primeira fase do direito constitucional inglês (Miranda, 1997, p. 122; García-Pelayo, 1999, p. 250; Mendes, 2000, p. 106). 
um sistema jurídico no qual inexistiam corpos legislativos sistemáticos e codificados ${ }^{9}$, desenvolve-se na Inglaterra o dever de levar em conta as decisões judiciais anteriores, o qual, segundo René David (1998, p. 341-342), é condensado nas três proposições seguintes:

1ํ- As decisões tomadas pela Câmara dos Lordes constituem precedentes obrigatórios, cuja doutrina deve ser seguida por todas as jurisdições, salvo excepcionalmente por ela própria; 2 - - As decisões tomadas pelo Court of Appeal constituem precedentes obrigatórios para todas as jurisdições inferiores hierarquicamente a este tribunal e, salvo em matéria criminal, para o próprio Court of Appeal; $3^{-}-$As decisões tomadas pelo High Court of Justice impõem-se às jurisdições inferiores e, sem serem rigorosamente obrigatórias, têm um grande valor de persuasão e são geralmente seguidas pelas diferentes divisões do próprio High Court of Justice e pelo Crown Court.

O fato de o Direito estar diluído nas decisões dos juízes explica por que, no ordenamento jurídico britânico, é infensa a idéia de um "poder” constituinte capaz de, per se, estabelecer e ordenar um novo modelo político para o povo (Canotilho, 1997, p. 69).

Por fim, convém observar que, por ser um sistema excessivamente formalista, no qual um direito poderia não ser conhecido e tutelado caso o remédio jurídico invocado para a sua proteção fosse o inadequado, desenvolveu-se, na Inglaterra, um sistema de recursos que seria julgado não segundo o direito, mas sim por meio da eqüidade (equity). Essa função essa, inicialmente, desempenhada pelo Rei e, posteriormente, pelo Tribunal de Chancelaria (David, 1998, p. 296, 333).

\subsubsection{A sobreposição institucional}

Outra característica peculiar a ser apontada no sistema do Reino Unido, de certo modo decorrente da repulsa a um “poder constituinte” que possa, por si só, estabelecer nova

9 É digno de nota observar que as leis, por muito tempo, foram vistas, no direito inglês, como mero modo de retificar alguma distorção na Common Law ou de criar alguma regra excepcional, razão pela qual deveriam ser interpretadas literalmente pelos tribunais (David, 1998, p. 345).

Mesmo o recurso à vontade do legislador era pouco utilizado no Reino Unido até 1992, ocasião do julgado Pepper v. Hart. Os recursos interpretativos consistiam nos seguintes: interpretação literal; recurso à vontade do legislador (mischief rule), quando o texto legal fosse obscuro ou ambíguo; golden rule, o qual permitia afastar a interpretação literal quando o significado usual do texto levasse a um resultado absurdo, repugnante ou inconsistente com o restante do ordenamento jurídico (Rolim, 2001, p. 179).

A vontade do legislador seria obtida mediante o emprego das quatro regras seguintes: "qual era o direito anterior à lei; qual era a sua falha ou necessidade então existente; qual era o remédio empregado pelo Parlamento; e qual era sua verdadeira razão" (Rolim, 2001, p. 178).

A partir de 1939, com a edição de diversas leis com caráter dirigente - a exemplo das relativas a previdência social ou a políticas econômicas -, ficou evidente que o modo tradicional de interpretação das leis precisaria ser revisto (David, 1998, p. 345-346). 
ordem jurídica, é a da sobreposição institucional, ou seja, da permanência, durante toda a história inglesa, de instituições distintas que compartilham o poder. Assim, as modificações do equilíbrio de poder no ordenamento inglês são ditadas pela modificação das funções entre um e outro órgão, sem ruptura institucional ou extinção de qualquer deles (Miranda, 1997, p. 125). Os órgãos a serem mencionados são os seguintes: a Coroa, a Câmara dos Lordes e a Câmara dos Comuns, que compõe o atual Parlamento britânico. Não chega a ser exagero afirmar que a história constitucional inglesa é a história do Parlamento (Miranda, 1997, p. 128).

Deve ser apontado que o Reino Unido viveu as três formas de governo em virtude da modificação de funções entre esses órgãos: até o século XVII, o Poder está concentrado nas mãos do Rei - período monárquico; após o século XVII e até o século XIX, a concentração dá-se na Câmara dos Lordes - período aristocrático; após o século XIX, a Câmara dos Lordes passa a ser o órgão preponderante - regime democrático (Miranda, 1997, p. 125).

A Coroa funciona como elemento de unidade político-jurídica do Reino Unido, o que ajuda a explicar por que o Reino Unido não possui uma constituição solene: as tradições inglesas e o respeito à Coroa tornam desnecessária a sua existência. Cabe ao detentor da Coroa a prática de atos de administração e jurisdição (García-Pelayo, 1999, p. 292-293), desempenhando papéis nas três funções estatais. Assim, por exemplo, o Rei pode legislar para certas colônias por meio de Cartas-Patentes (no âmbito do Legislativo), suspender um processo judicial (no âmbito do Poder Judiciário), ou comandar as Forças Armadas (no âmbito do Executivo) (García-Pelayo, 1999, p. 298).

A natureza jurídica da Coroa vem sendo discutida ao longo da história do Reino. Inicialmente, foi considerada uma corporação, um corpo político, composto pelo rei e pelos súditos. As pretensões monárquicas de possuir fonte de recursos independente do Parlamento levaram a considerar a Coroa como corporação unitária, entendida como uma associação de indivíduos diferentes ao longo do tempo, mas representada por apenas um deles por vez. Mais recentemente, a Coroa é tida como um trust ${ }^{10}$ do povo inglês, sendo a Rainha o trustee (García-Pelayo, 1999, p. 291-292).

10 "Negócio jurídico pelo qual uma pessoa ou mais pessoas transferem a outra - o trustee - coisa ou direito, para que essa o empregue com objetivo determinado, mas sem ter sobre ela a disposição legal e efetiva”. In: Trust, Academia Brasileira De Letras Jurídicas. Dicionário Jurídico. Planejado, organizado e redigido por J. M. Othon Sidou, com a colaboração (na edição príncipe) dos acadêmicos Machado Paupério, A. de Mendonça Lima, Sílvio de Macedo, Fernando Whitaker, Albino Lima, Jorge Alberto Romeiro e José da Silva Pacheco. 7. ed. Rio de Janeiro: Forense Universitária, 2001. 
O Parlamento, atualmente composto pelo Rei, pela Câmara dos Lordes e pela Câmara dos Comuns, é uma instituição fundamental no sistema jurídico do Reino Unido, sendo a soberania a sua característica principal (Dicey, 2004). Outra importante instituição inglesa é o Gabinete, composto por alguns, mas não por todos, os ministros, os quais são nomeados ou demitidos pelo Rei, mediante proposta do Primeiro Ministro, cabendo ao Gabinete a atribuição de dirigir politicamente o país (García-Pelayo, 1999, p. 301-303).

\subsubsection{Fontes das normas constitucionais}

O respeito à Coroa e a sobreposição institucional, conforme apontado, ajudam a explicar o porquê de o Reino Unido não dispor de uma Constituição editada em documento solene. Resta, então, indagar: de onde provêm as normas constitucionais e como podem ser encontradas? Elas encontram sede, conforme as lições de García-Pelayo, nas seguintes fontes:

a) na legislação (Statute Law) - trata-se de leis constitucionais em função da matéria por elas reguladas, sendo assemelhadas, no tocante aos aspectos formais, a todas as demais leis. Citam-se como exemplos a Magna Carta (1215), da Petition of Rights (1628), do Habeas Corpus Act (1679), da Bill of Rights (1689), do Settlement Act (1701), dos Atos de União da Escócia (1707) e da Irlanda, das Representantion of the People Act, das leis sobre o Parlamento (1911 e 1949), o Estatuto de Westminster, a Lei sobre os Ministros da Coroa (1937) (García-Pelayo, 1999, p. 285-286; Miranda, 1997, p. 129);

b) nas decisões judiciais (Case Law), que tanto têm como fundamento a Common Law o direito e os costumes do Reino reconhecidos judicialmente - como a interpretação que as cortes dão ao Statute Law (García-Pelayo, 1999, p. 285-286).

c) no costume - todas as demais instituições e regras características da Constituição Britânica que não podem ser encontradas nas fontes acima, a exemplo da existência do Primeiro Ministro, do Gabinete ou da convocação anual do Parlamento (GarcíaPelayo, 1999, p. 285-286).

\subsubsection{O controle da constitucionalidade no Reino Unido}

Duas considerações devem ser feitas acerca do controle da constitucionalidade no Reino Unido. A primeira é a de que, como já afirmado, não há, nesse sistema jurídico, uma constituição escrita. Por essa razão, em princípio, o Parlamento possui um poder praticamente 
ilimitado para editar novas leis, tendo em vista que as leis não podem ser afastadas sob a alegação de inconstitucionalidade (Thuronyi, 2003, p. 65). Apesar disso, desde o século XVII, os juízes promovem a análise da conformidade das leis editadas (statutory law) com a Common Law (Sampaio, 2002, p. 27, Miranda, 1997, p. 132).

A segunda consideração é a de que, com o advento da União Européia, as Cortes Inglesas têm sido chamadas a pronunciar-se sobre a desconformidade de suas leis internas com as normas comunitárias, as quais prevêem princípios consagrados constitucionalmente, a exemplo da vedação à discriminação (Thuronyi, 2001, p. 65).

\subsection{Normas tributárias}

O imposto sobre a renda nasce no Reino Unido em 1799, somente tendo sido possível a partir do momento em que houve um adimplemento quase voluntário por parte dos contribuintes (Levi, 1989, p. 123). Cumpre questionar como foi possível estabelecer, nos cidadãos britânicos, a vontade de pagar esse tributo, tendo em vista que, de outra forma, seria inviável a sua cobrança, pelos altos custos envolvidos em sua administração.

Levi aponta as seguintes razões que parecem explicar tal fato (1989, p. 125-140):

a) O século XVIII foi um período de grande crescimento econômico no Reino Unido, com mudanças qualitativas no mercado, o que possibilitava a reformulação do Sistema Tributário.

b) Conflitos externos sucessivos causaram problemas orçamentários - a Guerra dos Nove Anos (1688-1697), a Guerra da Sucessão Espanhola (1702-1714), a Guerra da Sucessão Austríaca (1739-1748), a Guerra dos Sete Anos (1756-1763), a Guerra de Independência dos Estados Unidos (1775-1784) e as Guerras Napoleônicas.

c) Os gastos constantes da Coroa, para fazer frente a guerras em curso ou a empréstimos contraídos para financiar os dispêndios com guerras passadas, faziam necessário o aprimoramento do Sistema Tributário, pois a arrecadação eficaz de impostos dava a garantia aos credores de que seriam pagos.

d) O aumento do Poder do Parlamento após a Revolução Gloriosa (1688) tornava obrigatório seu aval para a instituição de qualquer tributo, e, mais importante, sua discordância poderia implicar a extinção de um imposto existente;

e) Depois da mencionada Revolução, o Parlamento passou a participar mais ativamente da elaboração das políticas fiscais do Reino Unido; 
f) A administração fiscal tornou-se mais e mais eficiente no cumprimento de seu mister;

g) O governo conseguiu convencer a população de que a instituição de tal imposto seria necessária para custear uma guerra contra os franceses, o que tinha grande apelo popular. Por conta disso, surgiu como um imposto temporário ${ }^{11}$.

O apoio popular era necessário, tendo em vista que o imposto sobre a renda somente funciona adequadamente, entre outras razões, mediante o acesso do Fisco a informações sobre a vida econômica dos contribuintes e porque sua imposição respeitaria a capacidade contributiva (Levi, 1989, p. 140).

Aqui, estão os embriões de dois princípios constitucionais tributários ingleses: a mitigação do direito à intimidade frente ao Fisco, no que concerne ao exercício de suas funções arrecadatórias e a vedação ao confisco. Alguns dos mais conhecidos princípios teóricos que devem nortear a cobrança do imposto sobre a renda são encontrados nos trabalhos pioneiros de Adam Smith (1996, p. 282-284):

I. Os súditos de cada Estado devem contribuir o máximo possível para a manutenção do Governo, em proporção a suas respectivas capacidades, isto é, em proporção ao rendimento de que cada um desfruta, sob a proteção do Estado. (...)

II. O imposto que cada indivíduo é obrigado a pagar deve ser fixo e não arbitrário. A data do recolhimento, a forma de recolhimento, a soma a pagar, devem ser claras e evidentes para o contribuinte e para qualquer outra pessoa. (...)

III. Todo imposto deve ser recolhido no momento e da maneira que, com maior probabilidade, forem mais convenientes para o contribuinte. (...)

IV. Todo imposto deve ser planejado de tal modo, que retire e conserve fora do bolso das pessoas o mínimo possível, além da soma que ele carreia para os cofres do Estado.

Contudo, convém notar que encontrar os princípios constitucionais tributários do Reino Unido não é tarefa fácil. Duas são as dificuldades em tentar estabelecê-los. A primeira reside no fato de que inexiste uma Constituição formal nesse país, sendo a própria noção de norma materialmente constitucional algo impreciso para os ingleses, somente sendo descoberta mediante o recurso ao direito comparado (David, 1997, p. 73).

A segunda, em grande medida decorrente da primeira, é a de que, ao contrário do direito continental, baseado sobremaneira no uso de raciocínios dedutivos, regras gerais e

11 Tanto assim que, com o término das Guerras Napoleônicas em 1815, o imposto sobre a renda foi repelido no Reino Unido em 1815, tendo, contudo, retornado a partir de 1842. É interessante observar que uma das razões invocadas para questionar o imposto era a de que o Governo, aparentemente, não queria abrir mão dos meios de ter acesso aos registros sobre a vida privada dos cidadãos (Levi, 1989, p. 142). 
princípios abstratos, o direito inglês surge da interpretação dada pelas cortes às questões a elas trazidas, apresentando-se casuístico (Rolim, 2001, p. 49). Assim, um princípio reconhecido em determinado caso poderia ser afastado em outro, conforme as circunstâncias.

Assim sendo, essa seção será dedicada, eminentemente, a analisar as noções do conceito de renda e a noção do princípio da legalidade em matéria tributária, com a conseqüente abordagem da questão da anualidade, da analogia e da impossibilidade de retroatividade da lei.

\subsubsection{O conceito de renda}

Ainda que inexistam normas em sede constitucional que regulem o conceito de renda, essa é uma noção fundamental, por razões óbvias, que deve ser abordada ao tratar-se do imposto sobre a renda. Três são as noções existentes no direito comparado: a do acréscimo patrimonial, a da fonte e a do trust (Thuronyi, 2003, p. 235).

O Reino Unido adota os dois últimos conceitos (Thuronyi, 2003, p. 235). Na noção da fonte, somente são considerados como renda valores que podem ser associados diretamente a uma fonte produtora e, assim, não se considera como renda itens, tais como prêmios, indenizações, presentes recebidos ou ganhos de capital ${ }^{12}$. Conforme lição de Victor Thuronyi (2003, p. 237), citando Lawrence H. Seltzer:

a renda surge como um fenômeno físico e consiste na colheita anual (...) o capital também surge como um fato físico: é, predominantemente, a terra (...) A renda surge da atividade econômica dirigida (...) e pode ser obtida regularmente (...) Ganhos casuais, esporádicos ou inesperados, oriundos, por exemplo, da venda do solo ou de outros direitos de propriedade não negociados normalmente por seu proprietário, o recebimento de presentes ou assemelhados não se amoldam ao conceito de renda (...) Desprovidos de uma fonte regular, tal como uma fazenda ou um negócio mercantil, esses valores surgem de fatos isolados. Assim, não se pode realmente esperar que eles ocorram novamente em intervalos regulares. Um homem prudente, evidentemente, trataria essas duas fontes de recursos diferentemente. Ele consideraria as últimas como acréscimos ao seu patrimônio, mas indisponíveis para consumo. (2003, p. 237) ${ }^{13}$.

12 Os ganhos de capital são os obtidos com a disposição da própria fonte de renda (Thuronyi, 2003, p. 237).

13 Livre tradução de "Income appears to be a physical fact and to consist of the annual harvest... Capital also appears to be a physical fact: it is the land, predominantly... Income arises from purposeful economic activity... and recurs fairly, regularly... Casual, sporadic, and unexpected gains, whether derived from de sale of the land, other property not ordinarily dealt in by the recipient, gifts, or otherwise, did not fit into this concept of income... Lacking a continuing source, such as a farm or business enterprise, they arose from discrete events. Hence they could not reliably be expected to recur at regular intervals. A prudent man, the conclusion was, will therefore regard them differently from ordinary income. He will treat them as additions to his capital, not available for ordinary consumption. 
Já a noção do trust decorre do problema da alocação dos recursos decorrentes da administração de um trust. Nessa concepção, os recursos obtidos com a alienação dos ativos de um trust não devem ser considerados renda, tendo em vista que devem ser reinvestidos pelo trustee para futuros pagamentos de rendimentos (Thuronyi, 2003, p. 238).

Isso não significa, evidentemente, que os ganhos de capital não estejam sujeitos a qualquer tributação. Eles o estão, mas a outro tributo que não o imposto de renda. Em alguns casos, podem sujeitar-se a esse imposto, na chamada tributação cedular. Conforme noticia o International Bureau of Fiscal Documentation - IBFD, para efeito de tributação do imposto sobre a renda das pessoas jurídicas situadas no Reino Unido, a renda e os ganhos de capital estão sujeitos a regras inteiramente diferentes (IBFD, 2003, p. 6). Resta indagar como diferenciar um conceito do outro.

A tributação da renda vai levar em conta o resultado, positivo ou negativo, de uma atividade desenvolvida pelo sujeito passivo, a exemplo do comércio. Já os ganhos de capital são decorrentes de resultados de mesma natureza, alcançados pela fruição de ativos dos quais se tenha a posse ou a propriedade. Apesar da aparente primariedade do conceito, ele não se encontra definido na legislação inglesa, exceção feita, conforme noticia o IBFD, à norma antievasão, originando-se, por conseqüência, centenas de decisões judiciais, a fim de diferenci los em casos concretos (IBFD, 2003, p. 6). O mesmo Instituto fornece-nos singelo exemplo, o qual demonstra a importância da diferença: uma fábrica de máquinas de costura, ao realizar a venda de uma das máquinas, aufere renda, ao passo que uma indústria têxtil, ao alienar uma máquina de costura de seu ativo permanente, obtém ganho de capital (IBFD, 2003, p. 6).

O imposto de renda, estabelecido em 1789, no Reino Unido, considerava todas as rendas em seu conjunto, sendo substituído por um modelo com base em cédulas em 1803. Em 1842, foi reintroduzida a tributação global, ainda que baseada em estrutura cedular. Em 1918, foi editada lei, definindo diferentes espécies de renda e deduções para cada cédula, e, em 1922, o sistema foi simplificado, estabelecendo-se um sistema cedular com conceitos de renda e deduções unificados (Thuronyi, 2003, p. 26).

\subsubsection{Princípio da legalidade}

O princípio da legalidade, hoje consagrado universalmente em matéria tributária, tem suas origens na Magna Carta de 1215, quando estabeleceu que nenhum imposto ou 
contribuição poderia ser cobrado no Reino Unido sem o consenso do Parlamento, a menos que se destinasse a resgatar a pessoa do rei, a fazer de seu filho mais velho um cavaleiro ou, apenas uma única vez, a custear o casamento de sua filha mais velha (British Library, 2004) ${ }^{14}$.

Esse princípio foi reafirmado, em bases mais estritas, na Bill of Rights, nos seguintes termos: a cobrança, por período prolongado, de impostos, realizada a pretexto de que esses serão utilizados pela Coroa ou mediante a utilização das prerrogativas, sem o consentimento do Parlamento, é ilegal, assim como, também, o será aquela realizada de qualquer outro modo que requeira o consentimento na sua inexistência (Yale Law School, $2004)^{15}$.

\subsubsection{Princípio da anualidade}

Outro princípio associado ao anterior é o da anualidade. O imposto sobre a renda deve ser aprovado em todos os anos fiscais pelo Parlamento, como forma de assegurar que não haja cobrança de imposto sem o aval do povo e como eficiente meio de lembrar aos governantes que ele surgiu como um imposto temporário (Tiley, 2000, p. 28)

\subsubsection{Vedação à analogia}

Além dessas disposições, o entendimento jurisprudencial do Reino Unido é que a analogia é vedada, tendo em vista que as leis não criam princípios, mas apenas regras aplicáveis aos casos nela tratados e, na hipótese de existência de princípios no texto legal, a aplicação deles fica restrita aos diplomas legislativos que regulam a mesma matéria (Rolim, 2001, p. 179).

14 Tradução livre do autor do seguinte trecho:

(12) No 'scutage' or 'aid' may be levied in our kingdom without its general consent, unless it is for the ransom of our person, to make our eldest son a knight, and (once) to marry our eldest daughter. For these purposes only a reasonable 'aid' may be levied. 'Aids' from the city of London are to be treated similarly.

15 Tradução livre do autor do seguinte trecho:

That levying money for or to the use of the Crown by pretence of prerogative, without grant of Parliament, for longer time, or in other manner than the same is or shall be granted, is illegal; 


\subsubsection{Irretroatividade}

Até o ano fiscal de 1996-1997 ${ }^{16}$, o Reino Unido conviveu com um artifício que contornava a noção de irretroatividade da lei fiscal, consistente no seguinte: a lei aprovada para o ano fiscal 1995-1994, por exemplo, tomava, como medida, a renda obtida no ano fiscal 1993-1994, ou seja, partia-se da premissa de que a lei era aprovada no ano do lançamento, sendo nele vigente, mas se usava como base de cálculo a renda do ano anterior. Tal sistema não é mais adotado (Tiley, 2000, p. 135).

\section{CONSIDERAÇOES FINAIS}

O presente trabalho teve por objeto apresentar breves lineamentos sobre o dever fundamental de pagar imposto de renda no Reino Unido. Tal estudo justifica-se, sobretudo, pelo caráter pioneiro que as questões tributárias tiveram naquele país, bem como, dada a diversidade entre o sistema jurídico britânico e o brasileiro, pela contribuição aos estudos de direito comparado. Em razão da amplitude de tal empreitada, não se teve a pretensão de esgotar o assunto.

\section{REFERÊNCIAS}

ACADEMIA BRASILEIRA DE LETRAS JURÍDICAS. Dicionário Jurídico. 7. ed. Rio de Janeiro: Forense Universitária, 2001.

BLACKSTONE, William, Sir. Commentaries on the law of England. Oxford: Clarendon Press, 1769. Disponível em: <http://www.yale.edu/lawweb/avalon/blackstone/blacksto.htm>. Acesso em 24 jun. 2004.

BRITISH LIBRARY. Text of the Magna Carta. Disponível em: <http://www.bl.uk/ collections/treasures/magnatranslation.html>. Acesso em 23 jun. 2004.

CANOTILHO, J. J. Gomes. Direito constitucional e teoria da constituição. 4. ed. Coimbra: Almedina, 1997.

DAVID, René. O direito inglês. São Paulo: M. Fontes, 1997.

16 Diferentemente do Brasil, no Reino Unido , o ano fiscal vai de 6 de abril de um ano até 5 de abril do ano seguinte (Tiley, 2000, p. 28). 
Os grandes sistemas do direito contemporâneo. São Paulo: M. Fontes, 1998.

DICEY, A. V. Introduction to the study of the law of the Constitution. Disponível em: <http://www.constitution.org/cmt/avd/law_con.htm>. Acesso em 29 jun. 2004.

GARCÍA-PELAYO, Manuel. Derecho constitucional comparado. Introdução de Manuel Aragón. Madrid: Alianza Editorial, 1999.

ITERNATIONAL BUREAU OF FISCAL DOCUMENTATION. Survey on the Societas Europaea: Annex 15 - United Kingdom. Disponível em: <http://europa.eu.int/comm/taxation _customs/publications/reports_studies/ taxation/societas_europea/annex_15_uk.pdf $>$. Acesso em 17 jun. 2004.

LEVI, Margaret. Of rule and revenue. Berkeley: University of California Press, 1989.

MIRANDA, Jorge. Manual de direito constitucional. 6. ed. Coimbra: Coimbra, 1997.

NABAIS, Antonio Casalta. O dever fundamental de pagar impostos. Coimbra: Almedina, 1999.

ROLIM, Joáo Dácio. Normas antielisivas tributárias. São Paulo: Dialética, 2001.

SAMPAIO, José Adércio Leite. A constituição reinventada pela jurisdição constitucional. Belo Horizonte: Del Rey, 2002.

TILEY, John. Revenue law. Oxford: Hart Publishing, 2000.

YALE LAW SCHOOL. English Bill of Rights 1689: An Act Declaring the Rights and Liberties of the Subject and Settling the Succession of the Crown. Disponível em: $<$ http://www.yale.edu/lawweb/avalon/england.htm>. Acesso em 23 jun. 2004.

Prismas: Direito, Políticas Públicas e Mundialização

http://www.mestrado.uniceub.br/revistamestrado

Artigo recebido em 25/01/2006 e aceito para publicação em 13/03/2006

A revista Prismas: Direito, Políticas Públicas e Mundialização destina-se à publicação de artigos relacionados com a área jurídica, tem o propósito de difundir as reflexões dos pesquisadores, docentes, discentes, profissionais e estudantes da área de Ciências Jurídicas.

Os artigos são avaliados mediante processo de revisão por pares e deverão contemplar as reflexões que dizem respeito ao estudo do Direito, das Relações Internacionais e das Políticas Públicas. 